\title{
Ezrin Self-Association Involves Binding of an N- Terminal Domain to a Normally Masked C-Terminal Domain that Includes the F-Actin Binding Site
}

\author{
Ronald Gary* and Anthony Bretscher ${ }^{\dagger}$
}

Section of Biochemistry, Molecular and Cell Biology, Biotechnology Building, Cornell University, Ithaca, New York 14853

Submitted March 30, 1995; Accepted June 1, 1995

Monitoring Editor: Thomas D. Pollard

\begin{abstract}
Ezrin is a membrane-cytoskeletal linking protein that is concentrated in actin-rich surface structures. It is closely related to the microvillar proteins radixin and moesin and to the tumor suppressor merlin/schwannomin. Cell extracts contain ezrin dimers and ezrinmoesin heterodimers in addition to monomers. Truncated ezrin fusion proteins were assayed by blot overlay to determine which regions mediate self-association. Here we report that ezrin self-association occurs by head-to-tail joining of distinct $\mathrm{N}$-terminal and $\mathrm{C}$-terminal domains. It is likely that these domains, termed $\mathrm{N}$ - and C-ERMADs (ezrinradixin-moesin association domain), are responsible for homotypic and heterotypic associations among ERM family members. The N-ERMAD of ezrin resided within amino acids 1-296; deletion of 10 additional residues resulted in loss of activity. The C-ERMAD was mapped to the last 107 amino acids of ezrin, residues 479-585. The two residues at the C-terminus were required for activity, and the region from 530-585 was insufficient. The C-ERMAD was masked in the native monomer. Exposure of this domain required unfolding ezrin with sodium dodecyl sulfate or expressing the domain as part of a truncated protein. Intermolecular association could not occur unless the C-ERMAD had been made accessible to its $\mathrm{N}$-terminal partner. It can be inferred that dimerization in vivo requires an activation step that exposes this masked domain. The conformationally inaccessible C-terminal region included the F-actin binding site, suggesting that this activity is likewise regulated by masking.
\end{abstract}

\section{INTRODUCTION}

A variety of stimuli can cause actin-rich cell surface projections to form, often within minutes. However, the structural proteins that reorganize the cortical actin cytoskeleton during this process remain largely unknown. Key reorganizing proteins might be predicted to form new associations at the plasma membrane-cytoskeletal interface in response to signals from upstream regulators. Ezrin and related proteins are membrane-cytoskeletal linkers with many of the properties expected of such effectors.

\footnotetext{
* Present address: Life Sciences Division, M888, Los Alamos National Laboratory, Los Alamos, NM 87545.

${ }^{+}$Corresponding author.
}

Ezrin is the founding member of the ezrin-radixinmoesin (ERM) family of proteins, which share about 75\% amino acid sequence identity (Gould et al., 1989; Turunen et al., 1989; Funayama et al., 1991; Lankes and Furthmayr, 1991; Sato et al., 1992). These proteins are components of actin-rich surface projections such as microvilli, membrane ruffles, and lamellipodia in a variety of cell types (Bretscher, 1983; Pakkanen et al., 1987; Bretscher, 1989; Goslin et al., 1989; Sato et al., 1992; Berryman et al., 1993; Franck et al., 1993; Amieva et al., 1994; Takeuchi et al., 1994b). Considerable evidence indicates that these proteins link microfilaments to membranes. Ezrin was originally isolated as a component of the detergent-insoluble cytoskeleton of microvilli (Bretscher, 1983), and immunoelectron microscopy shows it to be intimately associated with the plasma membrane of the intact structures (Pakkanen 
et al., 1987; Berryman et al., 1993). Members of the ERM family associate with at least one integral plasma membrane protein, the extracellular matrix receptor CD44 (Tsukita et al., 1994). An F-actin binding site at the C-terminus of ezrin has been discovered using truncated fusion proteins (Turunen et al., 1994), although, paradoxically, purified full-length ezrin does not bind to F-actin in cosedimentation assays (Bretscher, 1983; Bretscher, 1991; Shuster and Herman, 1995). Overexpression of C-terminal portions of ezrin induces the formation of long actin-containing processes (Martin et al., 1995), and depletion of ERM family proteins using antisense oligonucleotides causes the disappearance of microvilli, indicating that these proteins are necessary for forming or maintaining these structures (Takeuchi et al., 1994b).

Ezrin may be subject to regulation by phosphorylation, because this modification has been observed repeatedly in conjunction with cortical reorganization. For example, treatment of A431 cells with epidermal growth factor (EGF) initiates the formation of ezrinand moesin-containing microvilli and membrane ruffles coincident with phosphorylation of ezrin on tyrosine and serine (Bretscher, 1989; Franck et al., 1993). Ezrin becomes phosphorylated on tyrosine in cells infected with Rous sarcoma virus (Kamps et al., 1986) and after $\mathrm{T}$ cell activation, probably through the action of the Src-related kinase Lck (Egerton et al., 1992; Thuillier et al., 1994). cAMP-mediated stimulation of gastric parietal cells induces a dramatic translocation of membrane to the apical surface, the appearance of microvilli containing ezrin, and phosphorylation of ezrin on serine (Hanzel et al., 1991).

The most abundant form of ezrin in cell extracts is the monomer, but dimers and ezrin-moesin heterodimers can also be observed (Ullrich et al., 1986; Pakkanen and Vaheri, 1989; Gary and Bretscher, 1993a). However, attempts to generate these dimeric species from monomers in solution have been unsuccessful (Gary and Bretscher, 1993a). The failure of monomers and dimers to interconvert in vitro suggests that they differ in a way that affects their capacity to associate. Nonetheless, ERM family proteins readily associate when assayed by blot overlay. In these assays, ezrin and moesin bind to themselves, to each other, and to radixin (Gary and Bretscher, 1993a; Andreoli et al., 1994; Gary, 1995). The demonstration by blot overlay of a high affinity interaction between soluble and electrophoretically resolved binding partners indicates that a regulatory barrier to dimerization is circumvented in this assay, providing a means to delineate the interacting domains.

In this study, we use a series of $\mathrm{N}$ - and C-terminally truncated ezrin constructs to identify regions responsible for self-association. Remarkably, monomeric ezrin possesses a conformationally hidden C-terminal domain that, when exposed, can bind to an N-terminal domain of a second molecule. The F-actin binding site of ezrin is contained within the masked region, which can account for discrepancies in F-actin binding reported for full-length versus truncated proteins. The masked C-terminal domain is an unusual structural feature that allows ezrin dimerization and perhaps cytoskeletal association to be regulated.

\section{MATERIALS AND METHODS}

\section{Cells and Reagents}

Plasmids were propagated and proteins were expressed in Escherichia coli strain DH $5 \alpha$ grown in Luria-Bertani broth with $100 \mu \mathrm{g} / \mathrm{ml}$ ampicillin. Full-length and C-terminal ezrin fusion proteins were purified from the lon,ompT protease-deficient strain BL21 (Novagen, Madison, WI). Cells were made competent by the polyethylene glycol method (Ausubel et al., 1994) or obtained as competent (Life Technologies, Gaithersburg, MD). A431 cells (American Type Culture Collection, Rockville, MD) were cultured in DMEM with $10 \%$ fetal bovine serum and antibiotics. Restriction enzymes and other reagents for molecular biology were purchased from Life Technologies, New England Biolabs (Beverly, MA), and Pharmacia Biotech (Piscataway, NJ). Biotinylated molecular weight markers were obtained from Sigma Chemical (St. Louis, MO).

\section{Construction of Plasmids}

Clone F6 (Gould et al., 1989) containing human ezrin cDNA in an Okayama-Berg vector (Okayama and Berg, 1982) was digested with NruI, then Spel linkers were added using T4 DNA ligase. The product was digested with Tth 111I, blunt-ended with mung bean single-strand specific exonuclease, and modified by XhoI linker ligation. Double digestion with Xhol/SpeI yielded a 2.04-kb Tth 111I-Nru I fragment of ezrin cDNA containing the entire coding sequence and possessing XhoI and SpeI cohesive overhangs at the $5^{\prime}$ and $3^{\prime}$ ends, respectively.

The unique Aat II site of the pGEX-3X expression vector (Pharmacia) was destroyed by Aat II digestion and mung bean nuclease treatment, then re-circularized. A duplex polylinker comprised of annealed synthetic oligomers 5'-GATCCAAGCTATGCATGATCCGCTCGAGCACGTGACTAGTGTTTCTAGAGACGTCG-3' and $5^{\prime}$ - AATTCGACGTCTCTAGAAACACTAGTCACGTGCTCGAGCGGATCATGCATAGCTTG-3' was inserted into the BamHI/EcoRI cloning site of the Aat $\mathrm{II}^{-}$vector. Finally, the 2.04-kb Tth 111I-Nru I ezrin cDNA fragment was cloned into the Xhol/SpeI site of the synthetic polylinker in-frame with glutathione-S-transferase (GST) to create the expression plasmid pRG32D (Figure 1A). Upon induction, pRG32D produces a fusion protein of GST $(27 \mathrm{kDa})$ linked to full-length ezrin by a 39-amino acid spacer (SDLIEGRGIQAMHDPLERRLRCCWIVVFSGIEDTHQKPK) coded for by pGEX vector and ezrin $5^{\prime}$-UTR sequences (Figure 1B).

Truncated fusion protein expression plasmids were derived from pRG32D by deletion of variable lengths of ezrin cDNA from either the 5' or $3^{\prime}$ end. Cleavage of pRG32D at its unique SpeI and Aat II sites created a linear plasmid with $5^{\prime}$ and $3^{\prime}$ overhang ends, which were susceptible and resistant, respectively, to digestion by exonuclease III. This linear plasmid $(1.5 \mu \mathrm{g})$ was treated with exo III $(5$ $\mathrm{U} / \mu \mathrm{l}$ ) at $28^{\circ} \mathrm{C}$ for $0-27 \mathrm{~min}$; aliquots were removed at 3-min intervals. The DNA from each aliquot was blunt-ended with S1 nuclease and DNA polymerase I Klenow fragment, then re-circularized and used for transformations. The resulting clones produced a series of truncated GST-ezrin fusion proteins with progressively larger deletions from the ezrin C-terminus (Figure 1C). The pGEX vector, which contains stop codons in all three reading frames, provided the stop codon for these proteins. Thus, there were typically 4,5 , or 7 vector-encoded amino acids after the C-terminal deletion. Fusion proteins with deletions from the $\mathrm{N}$-terminus of ezrin (Figure 1D) 
were prepared in a similar way, except that pRG32D was cleaved at unique Xhol and Nsi I sites to generate exo III-susceptible and resistant ends. These proteins used the endogenous ezrin stop codon, but only one of three constructs placed ezrin sequence in the same reading frame as GST. Clones expressing in-frame truncated fusion proteins were selected by sodium dodecyl sulfate-polyacrylamide gel electrophoresis (SDS-PAGE) analysis of total induced cell lysates. By screening clones derived from the appropriate exo III digestion timepoint, deletions of any size desired were targeted. All DNA constructs were sequenced using Sequenase Version 2.0 (United States Biochemical, Cleveland, $\mathrm{OH}$ ) or automated cycle sequencing (model 373A; Applied Biosystems, Foster City, CA).

Three additional plasmids were created that produced GST fusion proteins with ezrin amino acids 541-585, 530-585, and 474-583. To construct the first, pRG32D was cleaved at AvaI sites near codon 541 and in the synthetic polylinker. The $5.4-\mathrm{kb}$ fragment was bluntended by filling-in with Klenow and then re-circularized. To construct the second plasmid, a 0.41-kb PvuII-EcoRI fragment of ezrin cDNA was inserted into the SmaI/EcoRI site of pGEX-3X. This PvuII site was not evident in the ezrin sequence as originally published. Ezrin cDNA nucleotides 1710-1711 had been reported to be "CG" but are in fact "GC." This correction reveals the new PvuII site, and also changes the deduced amino acid sequence of human ezrin from valine to leucine at residue 531, making human, mouse, and rat proteins identical at this position. The third plasmid was designed to place a stop codon immediately after codon 583 to avoid extraneous vector-encoded residues at the $\mathrm{C}$-terminus. The coding region was made by polymerase chain reaction (PCR) using primers $5^{\prime}$ CGGGATCCCCCCCGTGTACGAGCCGGTGAGC-3' and $5^{\prime}$-AACACTAGTTTACTCGAACTCGTCGATGCGCTGC- ${ }^{\prime}$, which create BamHI and SpeI sites, respectively. The $330-b p$ PCR product was ligated with the $5.0-\mathrm{kb}$ BamHI-SpeI fragment of pRG32D to give the desired construct.

Human moesin was cloned from A431 cell total mRNA into the pCRII TA cloning vector (Invitrogen, San Diego, CA) according to the manufacturer's directions, using PCR primers 5'-CGAATTCCGCTGCCTTTGCCGCCA- $3^{\prime}$ and $5^{\prime}$-GTCTAGAGTGAGTTAGGTGAGGAGT $-3^{\prime}$. The insert was oriented with the $5^{\prime}$ end of the cDNA nearest the T7 promoter of the vector. Loss of the vector $3^{\prime}-\mathrm{T}$ overhang during cloning caused a reading frame shift that was corrected by excision of the 11-bp fragment between the vector EcoRI site proximal to the T7 promoter and the EcoRI site created by the $5^{\prime}$ PCR primer. The $1.8-\mathrm{kb}$ moesin cDNA was excised by XhoI-SpeI digestion and subcloned into the XhoI/SpeI site of a vector identical to pRG32D except containing $5^{\prime}$-AAGCTAGCTT-3' between the BamHI and Nsi I sites. The resulting plasmid produced a fusion protein of GST linked to full-length moesin by a 36-amino acid spacer (SDLIEGRGIQASLCMIRSSGRQCDGYLQNSAAFAAT).

\section{Production of Fusion Proteins}

Freshly saturated overnight cultures were inoculated at 1:10 or 1:40 dilution and grown for 60 or $90 \mathrm{~min}$ at $37^{\circ} \mathrm{C}$. Isopropyl $\beta$-D-thiogalactopyranoside was added to $0.1 \mathrm{mM}$ and growth was continued for an additional 90-240 min. To prepare total lysates, cells were harvested by centrifugation at $1500 \times g$ for $15 \mathrm{~min}$, resuspended in 0.05 volume Tris-buffered saline (TBS), lysed by addition of an equal volume of $2 \times$ SDS gel sample buffer, boiled $2 \mathrm{~min}$, and passed through a 28 -guage needle to reduce viscosity. To prepare purified fusion proteins, cells were resuspended in 0.025 volume TBS $/ 2 \mathrm{mM}$ EDTA $/ 2 \mathrm{mM}$ dithiothreitol $/ 0.5 \mathrm{mM}$ benzamidine $/ 0.25 \mathrm{mM}$ phenylmethylsulfonyl fluoride (PMSF) at $4^{\circ} \mathrm{C}$, lysed by 15 - to 30 -s sonication (Branson Sonifier W185-E, microprobe tip; Danbury, CT), and clarified at $16,000 \times g$ for $10 \mathrm{~min}$. Supernatants were applied to $S$-linked glutathione-agarose beads (Sigma) and incubated at $4^{\circ} \mathrm{C}$ for $1 \mathrm{~h}$ with gentle inversion. Beads were washed five times with TBS, and GST-fusion proteins were eluted with $10 \mathrm{mM}$ reduced glutathione (Sigma) in $50 \mathrm{mM}$ Tris- $\mathrm{HCl} / 150 \mathrm{mM} \mathrm{NaCl}(\mathrm{pH} 8.0$ before glutathione addition). Yields were sufficient even though $\mathrm{N}$-terminal ezrin fusion proteins were poorly soluble. The proteins often lost activity during storage, so they were generally prepared shortly before use.

\section{Gel Electrophoresis and Western Blots}

Protein samples were analyzed by SDS-PAGE on $11 \%$ gels following standard procedures (Ausubel et al., 1994). For Western blots, proteins were transferred to polyvinylidene fluoride membranes (Immobilon-P; Millipore, Bedford, MA) with a semi-dry electroblotter (Integrated Separation Systems, Hyde Park, MA) or applied to nitrocellulose as described for slot blots. Blots were blocked with $10 \%$ nonfat dry milk, incubated with 1:10,000 GST antiserum (Pharmacia) followed by $1: 10,000$ peroxidase-conjugated rabbit anti-goat IgG (Sigma). Immunoreactive bands were detected using enhanced chemiluminescence (ECL; Amersham, Arlington Heights, IL). To demonstrate that proteins giving negative blot overlay results had been transferred efficiently, blots were washed extensively after overlay analysis (described below), and then re-probed with GST antiserum to give the Western blots shown in Figures 2 and 3.

\section{Blot Overlays}

Human ezrin was purified from placenta as described (Bretscher, 1989), except that a gel filtration chromatography step was added and only the monomer fraction was used. Purified proteins were biotinylated as described (Gary and Bretscher, 1993a); fusion proteins were bound to glutathione beads during the reaction. Total cell lysates were resolved by SDS-PAGE, transferred to polyvinylidene fluoride membranes, and the resulting blots were blocked as described for Western blotting. Blots were incubated with biotintagged probes in $1 \%$ nonfat dry milk, $0.1 \%$ Tween-20, $25 \mathrm{mM}$ Tris- $\mathrm{HCl}, 150 \mathrm{mM} \mathrm{NaCl}, \mathrm{pH} 7.4$ for $4-12 \mathrm{~h}$ at $4^{\circ} \mathrm{C}$. This buffer was used without milk for washes and with $0.5 \%$ milk for incubation of secondary reagent, 1:2000 peroxidase-conjugated avidin (ExtrAvidin; Sigma). Probe binding was detected by ECL.

Probes were used at the following concentrations (because storage affected potency, conditions are noted for probes not prepared freshly before use): $0.1 \mu \mathrm{g} / \mathrm{ml}$ ezrin (stored at $-20^{\circ} \mathrm{C}$ in $50 \%$ glycerol; characterized in Gary and Bretscher, 1993a), $0.01 \mu \mathrm{g} / \mathrm{ml}$ GSTezrin, $0.03 \mu \mathrm{g} / \mathrm{ml} \mathrm{GST}$-moesin (stored frozen at $-70^{\circ} \mathrm{C}$ ), $0.1 \mu \mathrm{g} / \mathrm{ml}$ GST, $0.05 \mu \mathrm{g} / \mathrm{ml} \mathrm{b}-479-585$ and b-160-585, $0.01 \mu \mathrm{g} / \mathrm{ml} \mathrm{b}-1-439$, and $0.005 \mu \mathrm{g} / \mathrm{ml} \mathrm{b}-1-296$ and $\mathrm{b}-1-286$.

\section{Slot Blots}

Purified native fusion proteins were applied to nitrocellulose using a vacuum slot blot apparatus (Life Technologies). Blocking, probe incubation, and detection steps were the same as for overlays except that Tween-20 was omitted. For SDS pretreatment, probes were mixed with $50 \mu \mathrm{g} / \mathrm{ml} \mathrm{SDS}$, boiled $2 \mathrm{~min}$, then diluted to $1 \mu \mathrm{g} / \mathrm{ml}$ final SDS concentration before use.

\section{Immunoprecipitation}

Placental ezrin was subjected to SDS pretreatment as described above or left untreated, then mixed with bacterial lysate or $2 \mathrm{mg} / \mathrm{ml}$ final concentration bovine serum albumin (BSA). These mixtures were incubated for $2-3 \mathrm{~h}$ at $4^{\circ} \mathrm{C}$ with Protein A-Sepharose beads (Sigma) and either $10 \mu \mathrm{l}$ rabbit antiserum raised against human ezrin (Bretscher, 1989) or $3 \mu \mathrm{g}$ monoclonal antibody Z036 (Zymed Laboratories, South San Francisco, CA). Immunoprecipitates were washed with TBS and analyzed by SDS-PAGE.

\section{Affinity Bead Binding Assays}

Purified GST-fusion proteins bound to glutathione-agarose were used as affinity beads. Beads were incubated with $70 \mu \mathrm{g} / \mathrm{ml}(1.0$ $\mu \mathrm{M})$ or $20 \mu \mathrm{g} / \mathrm{ml}(0.3 \mu \mathrm{M})$ native placental ezrin, or $10 \mu \mathrm{g} / \mathrm{ml}(0.3$ 
$\mu \mathrm{M}) 35 \mathrm{kDa}$-terminal proteolytic ezrin fragment in TBS. BSA was added to all affinity bead mixtures to give $2 \mathrm{mg} / \mathrm{ml}$ final concentration. The affinity bead mixtures were incubated for $4 \mathrm{~h}$ at $4^{\circ} \mathrm{C}$ with gentle inversion. Beads were then washed five times with TBS, and bound proteins were eluted by boiling $2 \mathrm{~min}$ in $2 \times$ SDS gel sample buffer.

The 35-kDa fragment was generated from the full-length ezrin against which it was compared using a slight modification of a previously published method (referred to as $32 \mathrm{kDa}$ in Franck et al., 1993). Briefly, ezrin was digested with $10 \mu \mathrm{g} / \mathrm{ml} \alpha$-chymotrypsin for $2 \mathrm{~h}$ at $18^{\circ} \mathrm{C}$ and the reaction terminated by the addition of $4 \mathrm{mM}$ PMSF. Unlike $81-\mathrm{kDa}$ ezrin, the $35-\mathrm{kDa}$ fragment migrates by SDSPAGE in accordance with its true molecular weight and therefore constitutes about one-half of the mass of ezrin, as indicated in the molar concentration estimates.

\section{RESULTS}

\section{Expression of Ezrin Fusion Proteins}

Bacterial expression plasmid pRG32D (Figure 1A) produced a fusion protein comprised of GST and fulllength human ezrin (Figure 1B). Additional plasmids were derived from $p R G 32 D$ by unidirectional deletion of ezrin cDNA from either the $3^{\prime}$ or $5^{\prime}$ end. Bacterial clones carrying these plasmids made fusion proteins lacking portions of the ezrin C-terminus (Figure 1C) or N-terminus (Figure 1D), respectively. These proteins were obvious in total cell lysates analyzed by SDSPAGE (Figure 2A). The identities of the fusion proteins were confirmed by Western blotting with GST antibody (Figure 2B). Like natural ezrin, bacterially expressed ezrin fusion proteins migrated anomalously on SDS gels. Plots of $R_{f}$ versus log molecular weight showed that the region of ezrin responsible for retarding migration lies mainly between amino acids 479 530 (the usual convention, followed here, is to number ezrin from proline-1 to leucine-585, omitting the initiating methionine, which is post-translationally removed [Gould et al., 1989; Franck et al., 1993]).

\section{Ezrin Self-Association Involves a Domain at the C-Terminus}

The two types of blot overlay binding partners will be referred to as targets and probes: targets were transferred to blots after SDS-PAGE and probes were biotinylated for use in solution. The truncated ezrin fusion proteins were used to map the interacting regions of each type. All targets that possessed the 107-residue C-terminus of ezrin (amino acids 479-585) were able to bind to a full-length ezrin probe (Figure 2C). A target containing only 56 residues of the ezrin Cterminus (amino acids 530-585) had no binding activity. All targets with deletions from the C-terminal end were inactive, including one lacking only two residues. This protein had five vector-encoded residues (Arg-Ile-His-Arg-Asp) appended to ezrin amino acid 583. Thus, the inactivity of this target could be due to steric or charge effects attributable to these five residues rather than to the loss of an essential function provided by amino acids $584-585$ (Ala-Leu). To distinguish between these possibilities, we constructed a fusion protein lacking residues $584-585$ by introducing a stop codon at position 584 . This protein, containing ezrin residues $474-583$, was unable to bind to the ezrin probe even though the ezrin 474-585 fusion protein target was active (Figure 3), proving that the last two amino acids at the C-terminus were required for interaction of target and probe.

\section{An N-Terminal Domain of Ezrin Binds to the C-Terminal Domain}

The GST-ezrin fusion protein was comparable to natural ezrin from placenta when the two were used as

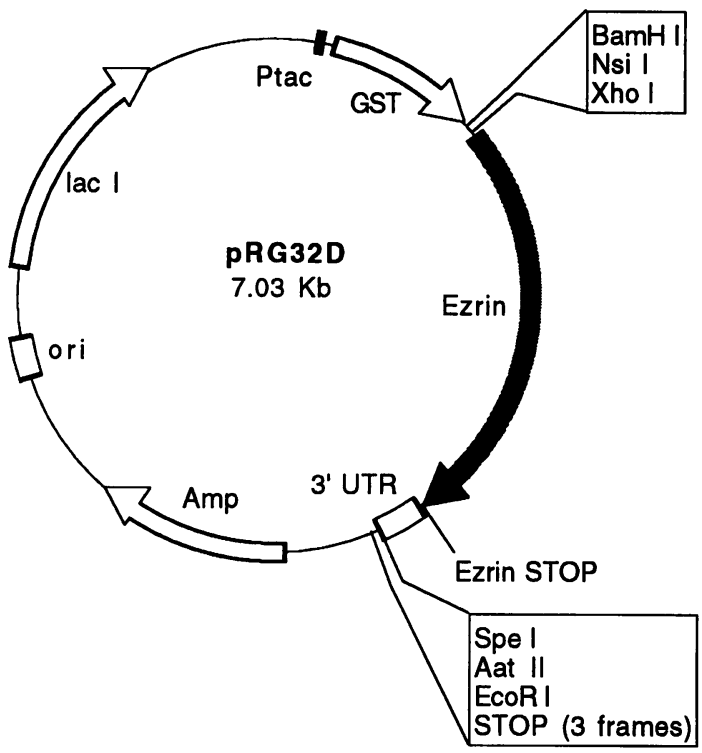

B

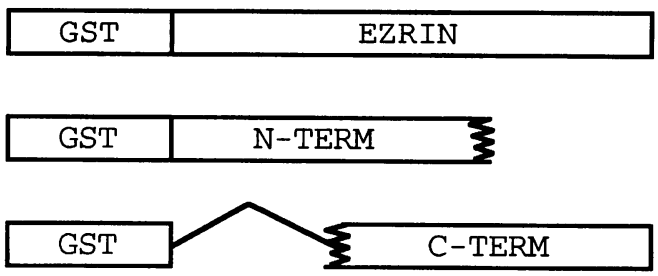

Figure 1. Production of fusion proteins. (A) Ezrin CDNA was subcloned into a $p G E X-3 X$ vector to create plasmid $p R G 32 D$. The cDNA is flanked by pairs of unique restriction sites that allow unidirectional deletion from either end. (B) Full-length GST-ezrin fusion protein produced by pRG32D. (C) Plasmids derived from SpeI/Aat II-cut pRG32D produced truncated fusion proteins with $\mathrm{C}$-terminal ezrin deletions of varying lengths. These proteins used a stop codon from the pGEX-3X vector. (D) Plasmids derived from Nsi I/XhoI-cut pRG32D produced truncated fusion proteins with $\mathrm{N}$-terminal ezrin deletions of varying lengths. These proteins used the endogenous ezrin stop codon. 


\section{A Coomassie}

\section{B GST Western}

\section{Ezrin Overlay}

Figure 2. A blot overlay target containing amino acids 479-585 of the ezrin C-terminus is sufficient to bind an ezrin probe. (A) Coomassie-stained SDS gel of total induced bacterial lysates. The cells expressed full-length or truncated GST-ezrin fusion proteins containing ezrin amino acids $1-585,160-585,325-585,368-585,428-585,474-585$, $479-585,530-585,555-585$, GST alone, 1-108, 1-218, 1-286, 1-296, 1-368, 1-439, 1-513, 1-543, 1-583, and 1-585 (lanes $1-20)$. Fusion proteins are evident as prominent clone-specific bands. Molecular masses (kDa) are shown at left. (B) Western blot of lysates (one-tenth amount shown in Coomassie gel) probed with GST antibody. The fusion proteins were recognized, along with a $72-\mathrm{kDa}$ background band. (C) Blot overlay of lysates probed with biotin-tagged ezrin A diagram of GST-ezrin fusion proteins is shown with bar lengths proportional to number of amino acids, not SDSPAGE migration distance. Deletions are indicated by a bent line (N-terminal) or gap (C-terminal).
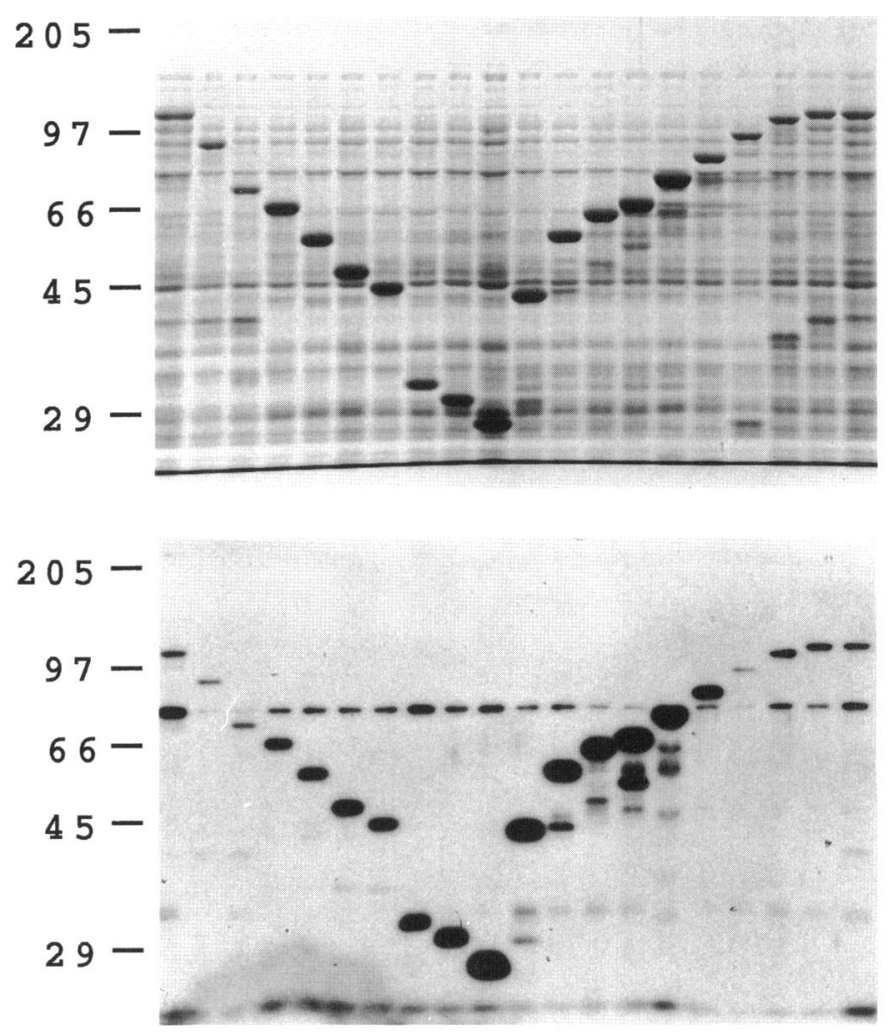

$205-$

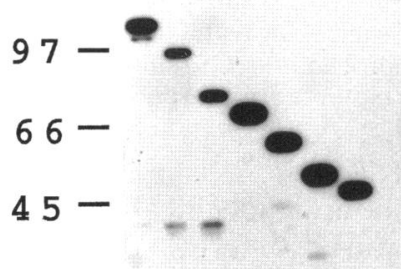

$29-$

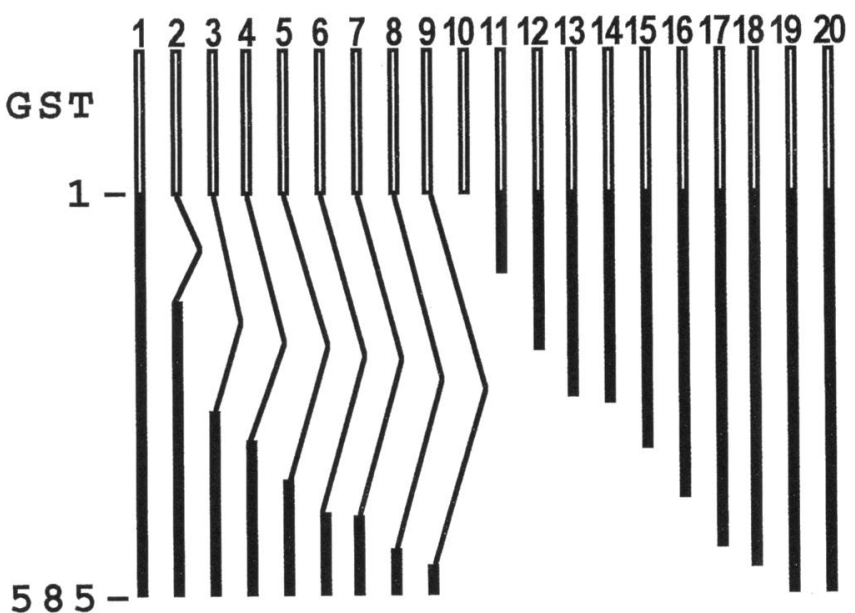


A

\section{Coomassie}
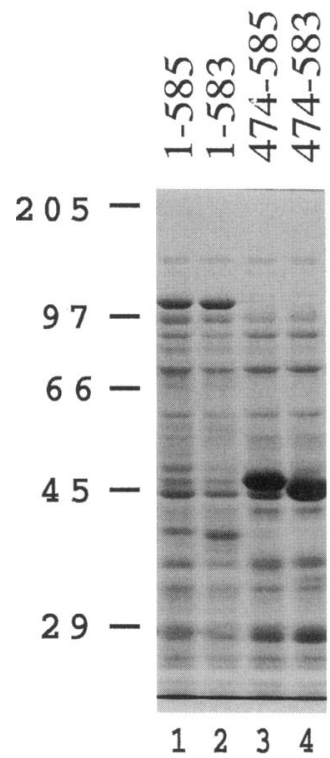

B
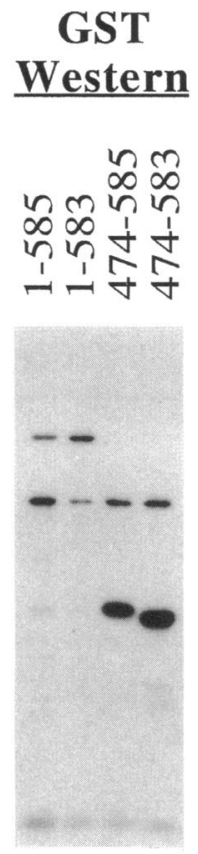

$\begin{array}{llll}1 & 2 & 3 & 4\end{array}$
C
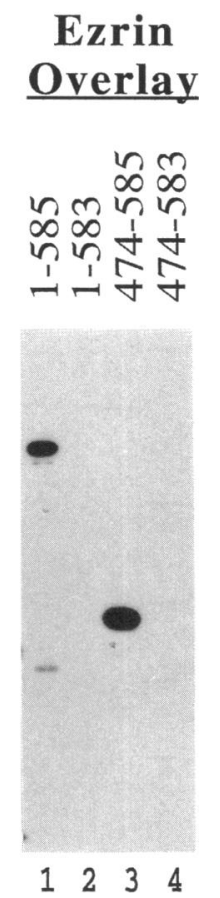

Figure 3. The last two residues at the C-terminus of ezrin are required for binding to an ezrin probe. (A) Coomassie-stained SDS gel of total induced bacterial lysates. The cells expressed fusion proteins containing ezrin amino acids 1-585, 1-583, 474-585, and 474-583 (lanes 1-4). Additional non-ezrin residues are present at the C-terminus of the fusion protein in lane 2 only. Molecular masses $(\mathrm{kDa})$ are shown at left. (B) Western blot of lysates (onetenth amount shown in Coomassie gel) probed with GST antibody. (C) Blot overlay of lysates probed with biotin-tagged ezrin.

probes in blot overlays. Each bound specifically to ezrin targets containing the required C-terminal domain (Figure 4, B and C). Moesin probes displayed the same target specificity as did ezrin, whether made from bacterial (Figure 4D) or placental proteins. In contrast, a biotinylated probe made from GST alone did not bind to overlay targets (Figure $4 \mathrm{E}$ ).

Truncated ezrin fusion proteins were used as probes to identify the region that binds to overlay targets. Surprisingly, an N-terminal portion of ezrin was required for this activity (Figure 5). Probes containing ezrin amino acids 479-585 (the shortest active target) or 160-585 were inactive. However, probes with an intact ezrin N-terminus, such as the amino acid 1-439 fusion protein, bound specifically to suitable targets. Ezrin amino acids 1-296 were sufficient for probe activity, but shorter regions such as 1-286 were essentially inactive by comparison. The ability of various fusion proteins to function as probes and targets is summarized (Figure 6). The shortest ezrin sequence active as a probe was amino acids 1-296, whereas for targets, this region was 479-585. Thus, ezrin self-as-

sociation involves the interaction of nonoverlapping $\mathrm{N}$-terminal and C-terminal domains. Because bacterially expressed probes and targets were each active, the interaction of the two domains does not require eukaryotic post-translational modifications.

Although the binding activity of targets survived SDS-PAGE, probes were quite labile. For example, the activity of the ezrin 1-296 probe was dramatically reduced by freezing and thawing (Figure 5G); other probes behaved similarly. SDS treatment rendered probes completely inactive. Thus, only the SDS-resistant C-terminal domain could function as a target after SDS-PAGE.

\section{The C-Terminal Association Domain Is Masked in Native Ezrin}

A slot blot assay was developed to study the interactions of native binding partners. Fusion proteins containing $\mathrm{N}$-terminal or C-terminal association domains were immobilized and then incubated with biotinylated probes (Figure 7). All proteins were purified and assayed in the absence of denaturants or detergents, except for SDS-pretreatment of probes where indicated. Native N-terminal and C-terminal domains bound to each other, but not to themselves. As expected, the activity of the $\mathrm{N}$-terminal but not the Cterminal domain was abolished by SDS pretreatment. Self-association of GST moieties was insignificant under the conditions employed. The native placental ezrin probe bound to immobilized proteins containing the C-terminal domain, but was unable to bind to native $\mathrm{N}$-terminal domains. This inability indicates that the C-terminal domain of native ezrin is inaccessible. Pretreating the ezrin probe with SDS enabled it to bind to $\mathrm{N}$-terminal domains, presumably because SDS unfolded ezrin and thereby exposed its previously masked C-terminal domain. SDS concomitantly inactivated the $\mathrm{N}$-terminal domain of ezrin, consistent with its effect on truncated ezrin probes containing this domain.

Immunoprecipitation experiments confirmed that a $\mathrm{C}$-terminal region that includes the $\mathrm{C}$-terminus is masked in the native ezrin monomer (Figure 8). Polyclonal antibodies immunoprecipitated a C-terminal ezrin fusion protein and full-length placental ezrin under all conditions tested. In contrast, a monoclonal antibody (Z036) raised against a synthetic peptide corresponding to ezrin amino acids 576-585 recognized its epitope in truncated but not full-length native ezrin, showing that the C-terminus is inaccessible in the latter. However, Z036 was able to immunoprecipitate ezrin that had been pretreated with SDS to expose the C-terminus. 
A
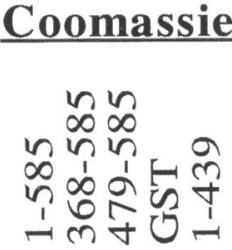

B
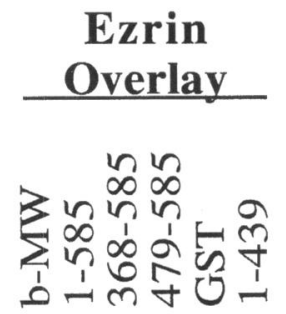

C
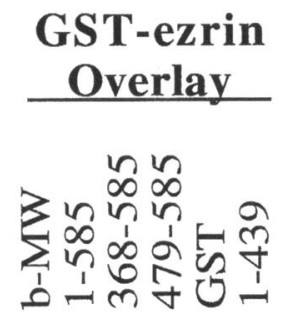

D
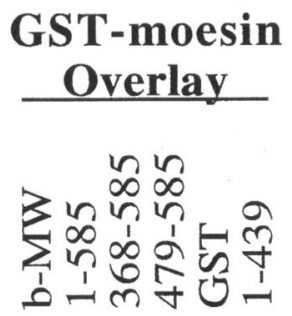

E

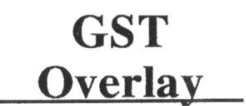

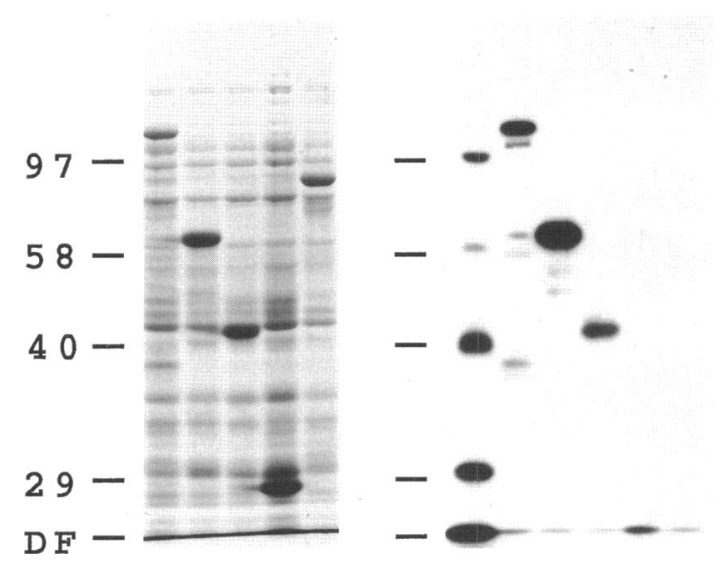
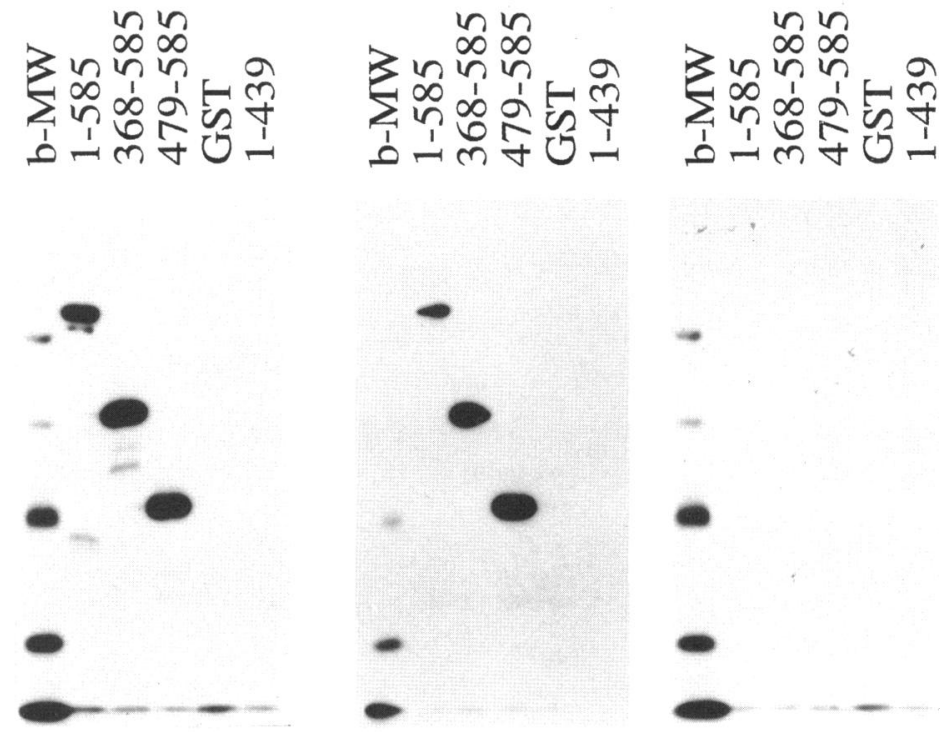

Figure 4. Bacterially expressed ezrin and moesin fusion proteins are equivalent to placental ezrin as overlay probes. (A) Coomassie-stained SDS gel of total induced bacterial lysates. The cells expressed fusion proteins containing ezrin amino acids 1-585, 368-585, 479-585 (positive overlay targets), GST alone, and 1-439 (negative controls). Molecular masses (kDa) and dye front (DF) are shown at left. (B-E) Biotinylated molecular weight markers (b-MW) and lysates (one-tenth amount shown in Coomassie gel) were resolved by SDS-PAGE, transferred to blots, and incubated with biotin-tagged ezrin (B), GST-ezrin fusion protein (C), GST-moesin fusion protein (D), or GST (E) probes. The ezrin, GST-ezrin, and GST overlays were performed in parallel; a shorter exposure was used for the GST-moesin overlay, which was done separately.

\section{The N-Terminal Association Domain May Be Only Partially Active in Native Ezrin}

Consistent with its activity as a probe in blot overlay and slot blot assays, placental ezrin bound to affinity beads that contained the C-terminal association domain (Figure 9A). Unmodified ezrin bound to beads containing the ezrin $479-585$ fusion protein, but not to GST alone. To confirm the specificity of this interaction, affinity beads were made from a matched pair of fusion proteins that differed only in the presence or absence of ezrin amino acids 584-585. Ezrin bound only to the affinity beads that possessed the last two residues of the $\mathrm{C}$-terminus, mirroring the blot overlay data in Figure 3. Degradation products that were present in the placental ezrin fraction also displayed specific binding, presumably because they contained the $\mathrm{N}$-terminal association domain. Although clearly specific, the overall efficiency of ezrin binding to affinity beads was unexpectedly poor; only $\sim 5 \%$ of the total ezrin remained bound to the beads under the best of circumstances. This raised the possibility that only a subpopulation of the placental ezrin might have been capable of binding to the affinity beads. The ezrin that bound to the beads must have had a functional $\mathrm{N}$ - terminal association domain to have bound specifically; to test whether this population of ezrin also possessed a functional C-terminal association domain, the bead-bound material was transferred to a blot and assayed for target activity by blot overlay (Figure 9A, lanes $\left.7^{\prime}-9^{\prime}\right)$. The fusion proteins used to make the affinity beads behaved in this assay as previously characterized and, as expected, the placental ezrin degradation products that had been bound to the beads were not recognized by the overlay probe because they lacked C-termini. However, the intact placental ezrin that had been bound to the beads was fully active as an overlay target, confirming that it possessed functional C-terminal as well as $\mathrm{N}$-terminal association domains and was thus authentic fulllength ezrin.

Although full-length ezrin could bind to affinity beads that contained the C-terminal domain, an $\mathrm{N}$ terminal ezrin fragment bound to the beads more efficiently. Limited $\alpha$-chymotrypsin digestion of ezrin generates a protease-resistant $35-\mathrm{kDa}$ fragment that has been shown by peptide sequencing to have an intact N-terminus (Franck et al., 1993). Equimolar concentrations of this $35-\mathrm{kDa}$ N-terminal fragment and 


\section{PROBES}

A

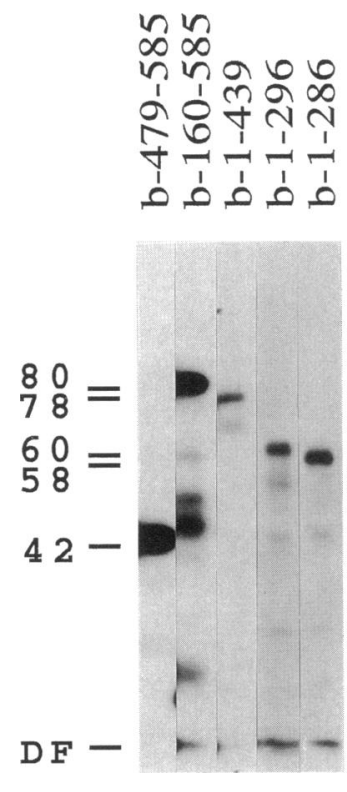

$\begin{array}{lllll}1 & 2 & 3 & 4 & 5\end{array}$

Figure 5. An N-terminal region of the ezrin probe binds to $\mathrm{C}$-terminal ezrin overlay targets. (A) The relative concentrations of biotinylated (b-) probes are shown. GST fusion proteins containing ezrin amino acids 479-585 (42 kDa), 160$585(80 \mathrm{kDa}), 1-439(78 \mathrm{kDa}), 1-296(60$ $\mathrm{kDa})$, and 1-286 (58 $\mathrm{kDa})$ were purified and biotinylated for use as probes. An amount of probe equal to that contained in $0.8 \mathrm{ml}$ of overlay solution (used in B-G) was subjected to SDS-PAGE, transferred to a blot, and detected with avidin-conjugated peroxidase and ECL (lanes 1-5). The inactive probes $b-479-585$ and $b-160-585$ were used at fivefold higher concentration than b-1-439, which was active (lanes 1-3). Probes b-1-296 (active) and b-1-286 (virtually inactive) were used at similar concentrations (lanes 4 and 5; a longer exposure was necessary to observe these bands). Molecular masses ( $\mathrm{kDa}$ ) and dye front (DF) are shown at left. (B-G) Biotinylated molecular weight markers (b-MW) and target lysates were transferred to replica blots as described in Figure 4, and then incubated with the biotin-tagged probes characterized in panel A. All probes were freshly prepared; in panel G, the probe was frozen and thawed once before use $(F / T)$, resulting in greatly diminished potency. A longer exposure was used for blots E-G than for B-D.
B
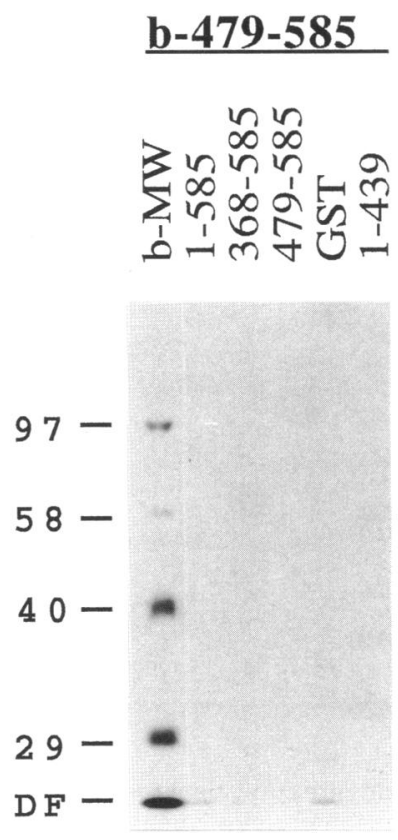

$\mathbf{E}$ b-1-296

\section{OVERLAYS}

C

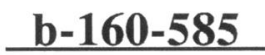

b-1-439
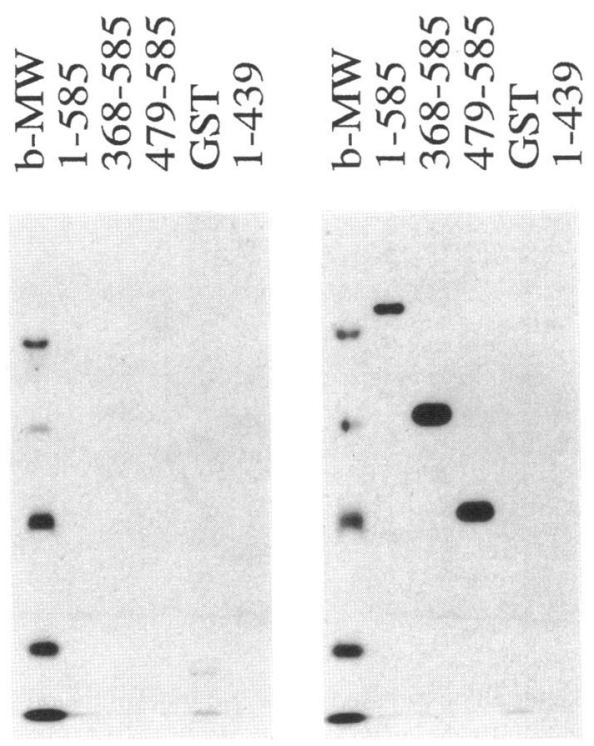

F

G
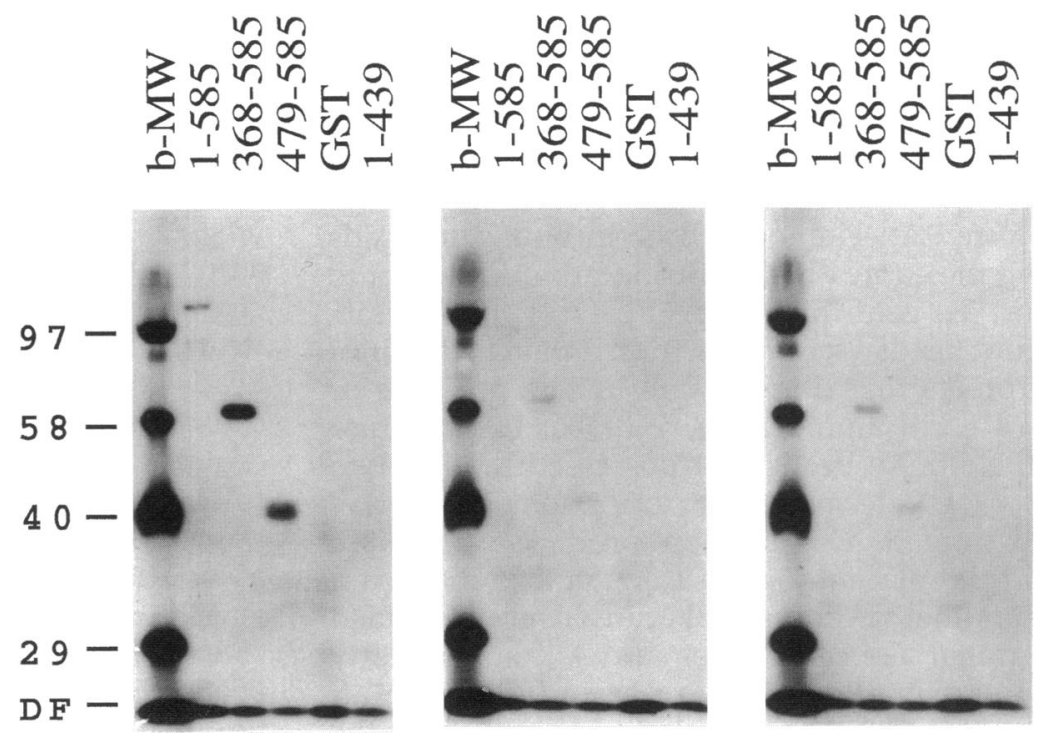
Figure 6. Summary of self-association domain mapping results. GST fusion proteins containing ezrin amino acid residues as indicated were assayed for activity as blot overlay targets and probes. Targets were transferred to blots after SDS-PAGE, and probes were used in solution. ND, not done. A schematic of ezrin indicates the smallest active N-terminal (crosshatched) and C-terminal (shaded) self-association domains, the polyproline motif (pp), and the F-actin binding site (act).

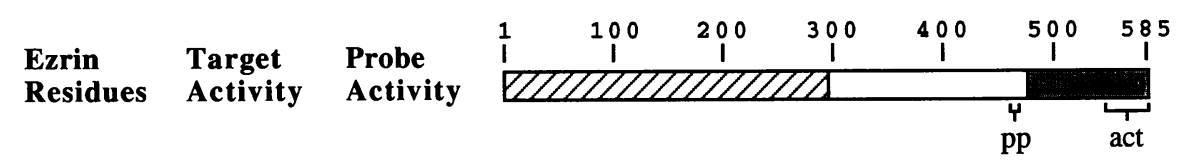

$1-585$
$1-583$
$1-572$
$1-543$
$1-513$
$1-439$
$1-368$
$1-336$
$1-333$
$1-296$
$1-286$
$1-283$
$1-218$
$1-108$
$160-585$
$325-585$
$368-585$
$428-585$
$474-585$
$474-583$
$479-585$
$530-585$
$541-585$
$555-585$

+
-
-
-
-
-
-
-
-
-
-
+
+
+
+
+
+
-
-

+
+
ND
ND
+
+
+
+
+
+
ND
-
ND
-
-
-
-
ND
ND
ND
ND
ND

The $\mathrm{N}$ - and C-ERMADs of ezrin have markedly different properties that allow a clear operational distinction between them. The N-ERMAD is quite labile; its activity was reduced by freeze thawing and completely destroyed by SDS treatment. In contrast, CERMAD activity withstood boiling in SDS. Thus, targets subjected to SDS-PAGE and transferred to blots manifest C-ERMAD activity exclusively. Because only complementary domains associate, probes used on such targets necessarily assay for N-ERMAD activity.

In a preliminary report analyzing ezrin after chemical cleavage in vitro, we showed that target activity resided in the C-terminal one-half of the molecule (Gary and Bretscher, 1993b), consistent with the results presented here. However, our results are in only partial agreement with a recent report from another laboratory that included preliminary domain mapping of ezrin (Andreoli et al., 1994). In that study, expressed ezrin fragments comprising residues 1-309 or 280-585 were subjected to SDS-PAGE, transferred to nitrocellulose, and incubated with iodinated ezrin probe. The probe bound to both halves of ezrin, with preference for the $\mathrm{N}$-terminal target. The reason for the difference between these results and ours is not yet evident. A coexpression bioassay has been used to identify an $\mathrm{N}$-terminal portion of ezrin (residues 
A

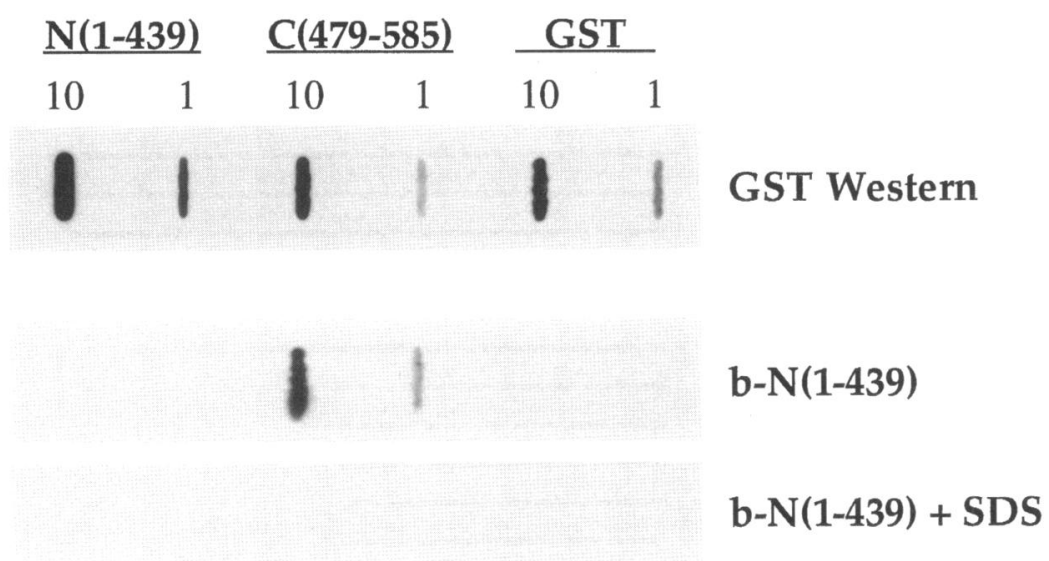

b-C(479-585)

b-C(479-585) + SDS Figure 7. Characterization of N-terminal and C-terminal domain interactions by native slot blot analysis and discovery of masked C-terminal domain in ezrin. (A) Purified native GST fusion proteins containing the $\mathrm{N}$-terminal domain (ezrin amino acids 1-439), the C-terminal domain (479$585)$, and GST alone were applied to nitrocellulose at relative amounts 10 and 1 using a vacuum slot blotter (columns). The nitrocellulose strips were analyzed by Western blot with GST antibody or incubated with biotinylated (b-) N-terminal or C-terminal probes (rows). Where indicated, the probes were treated with SDS before incubation. (B) Two purified native fusion proteins containing the $\mathrm{N}$-terminal domain (ezrin amino acids $1-513$ and $1-439$ ), two containing the C-terminal domain (428-585 and 479-585), and GST alone were applied to nitrocellulose (columns). The strips were incubated with native

b-ezrin + SDS or SDS-pretreated placental ezrin probes (rows).

1-115) that inhibits the morphogenic activity of overexpressed C-terminal ezrin fragments (Martin et al., 1995); it is not yet known whether this phenomenon involves ERMAD-mediated interactions, although the inhibitory region is considerably smaller than the $\mathrm{N}$ ERMAD domain mapped by blot overlay.

\section{The C-ERMAD Is Masked in Native Monomeric Ezrin}

The C-ERMAD activity was contained within ezrin residues 479-585, and 584-585 were essential for binding. At least part of the essential region was buried or otherwise inaccessible (masked) in the native monomer, as determined by both slot blot and immu- noprecipitation assays. Native ezrin could bind to neither N-ERMAD-containing proteins, which recognize the C-ERMAD, nor to monoclonal antibody Z036, which recognizes residues 576-585. However, the masked region could be exposed by unfolding ezrin with SDS to reveal both the active C-ERMAD and the Z036 epitope at the C-terminus.

Because neither N-ERMADs nor C-ERMADs could bind to themselves, the masking of the C-ERMAD in the native ezrin monomer precludes association with a second monomer. For this reason, monomers cannot be made to dimerize by simply increasing their concentration (Berryman and Bretscher, unpublished observation). In the blot overlay assay, SDS treatment of 


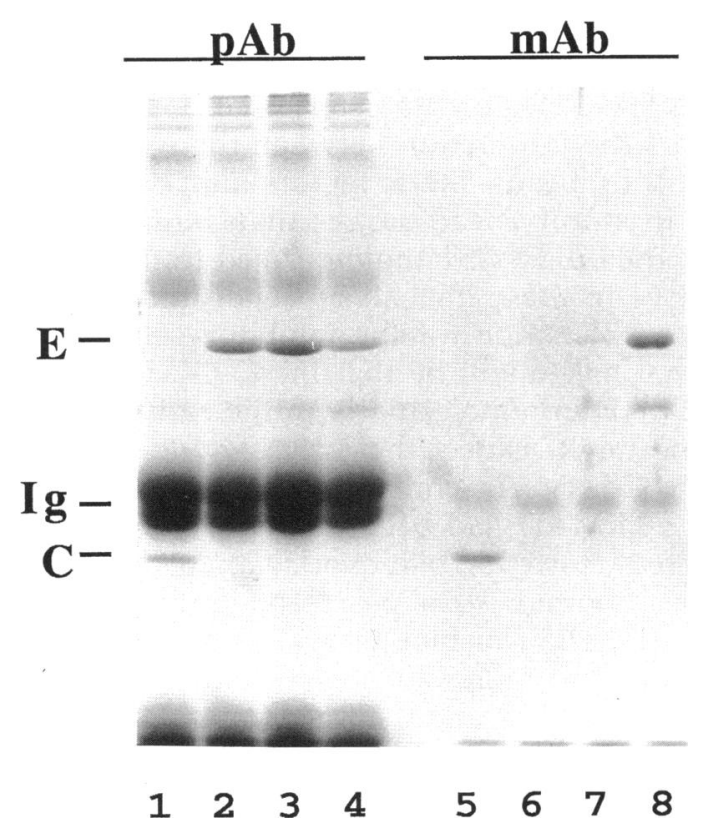

Figure 8. The C-terminus of native ezrin is inaccessible to antibodies but can be exposed by SDS treatment. Full-length or truncated ezrin was immunoprecipitated using polyclonal (pAb) ezrin antiserum (lanes 1-4) or an anti-peptide monoclonal antibody (mAb) that recognizes the ezrin C-terminus (lanes 5-8). Immunoprecipitation was performed on bacterial lysate from cells expressing the GST-ezrin amino acids 479-585 fusion protein (lanes 1 and 5), lysate from cells expressing GST alone mixed with purified placental ezrin (lanes 2 and 6), a mixture of BSA and ezrin (lanes 3 and 7), or BSA and SDS-treated ezrin (lanes 4 and 8). Immunoprecipitates were analyzed by SDS-PAGE and Coomassie blue staining. The C-terminal fusion protein (C), ezrin (E), and Ig heavy chain (Ig) bands are indicated.

ezrin before gel electrophoresis liberates the masked C-ERMAD and activates the protein for subsequent intermolecular association. The existence of endogenous dimers implies that some process can occur within cells to expose the C-ERMAD. The triggering event that induces this conformational change is unknown, but phosphorylation of ezrin is an obvious possibility that needs to be examined. The concept of triggered dimer formation is supported by the observation that EGF stimulation of cells can rapidly increase the proportion of dimeric ezrin (Berryman, Gary, and Bretscher, unpublished observation).

\section{F-Actin Binding Site Accessibility in Ezrin}

Masking of the C-terminus of ezrin has implications for F-actin binding. Affinity chromatography using truncated fusion proteins has shown that the C-terminal 34 residues of ezrin bind to F-actin, and that the last six residues are required for this interaction ( $\mathrm{Tu}-$ runen et al., 1994). The F-actin binding of full-length ezrin was not tested in these experiments, but it seems unlikely that it would display this activity given that the C-terminal 10 amino acids are not accessible to the Z036 monoclonal antibody. Consistent with this model, purified full-length ezrin does not bind to Factin in cosedimentation assays done at physiological ionic strength (Bretscher, 1983, 1991; Shuster and Herman, 1995). Similarly, moesin has a C-terminal F-actin binding site that can be observed in blot overlays, but native moesin does not bind F-actin when assayed in solution (Pestonjamasp et al., 1995). Thus, it appears that both C-ERMAD and F-actin-binding activities are masked in native ERM protein monomers. Accordingly, the triggering event that exposes the C-ERMAD in vivo could concomitantly release a hidden F-actin binding site. Experiments are under way to determine whether there is competition or cooperativity in the binding of N-ERMAD and F-actin ligands to C-ERMADs, and also to assess the ability of dimeric ezrin to bind to F-actin.

Our results may explain the surprising subcellular localization of the ezrin C-terminus when expressed in truncated form in cultured cells. The ezrin amino acid 280-585 fragment colocalizes with cortical and stress fiber F-actin in transfected cells (Algrain et al., 1993). In contrast, expressed full-length ezrin and endogenous ezrin associate with cortical F-actin but never with stress fibers (Bretscher, 1983; Sato et al., 1992; Algrain et al., 1993; Franck et al., 1993). The critical distinction between full-length and truncated proteins must be that the latter has lost normal regulation of its Cterminal accessibility. C-terminal exposure in fulllength ezrin may be restricted spatially and temporally, whereas exposure is constitutive in the truncated variant. The transfection experiment demonstrates that the C-terminal site has the capacity to bind to actin-containing stress fibers. However, it may be that the unmasking of this site is catalyzed at a location distant from stress fibers, for example the apical plasma membrane, so that actin binding is normally restricted to the cortical cytoskeleton. Regulated unmasking of an F-actin-binding site might also account for the tantalizing observation that ezrin from "motile" but not "stationary" cytoplasm can bind to Factin affinity columns (Shuster and Herman, 1995).

\section{Subtle Factors Appear to Influence N-ERMAD Activity}

The affinity bead binding data indicate that the issue of N-ERMAD accessibility or activity in native ezrin may be complex. Full-length placental ezrin bound specifically to C-ERMAD beads, indicating the utilization of an active N-ERMAD. However, the efficiency of this binding was low compared with that of a $35-\mathrm{kDa}$ proteolytic fragment containing the $\mathrm{N}$ ERMAD. The finding that the N-ERMAD is apparently less active when present in full-length ezrin 


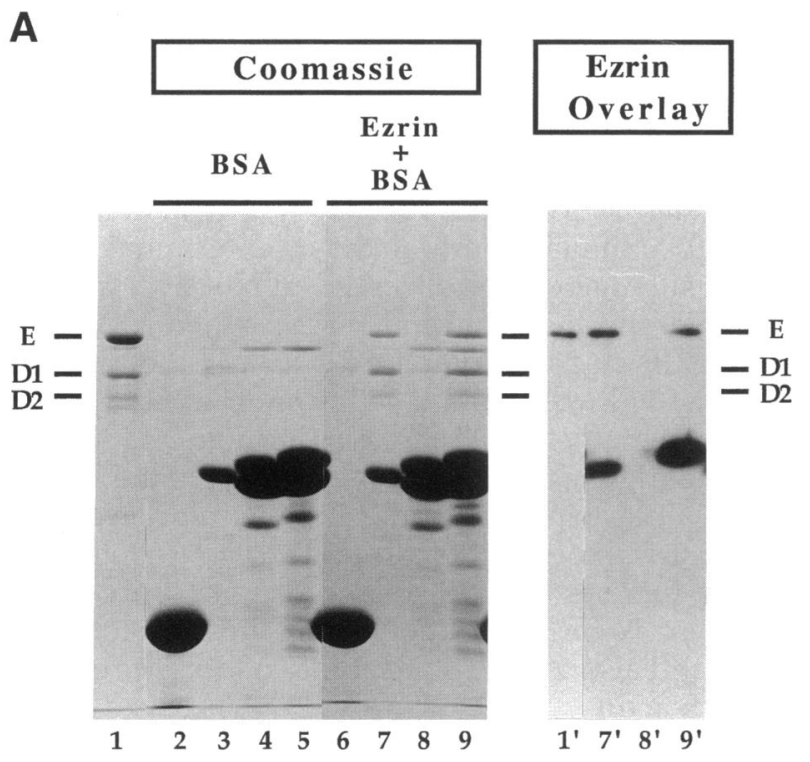

B

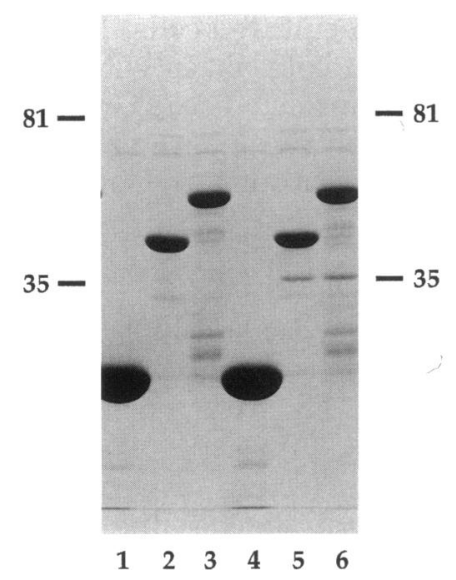

Figure 9. Full-length ezrin binds to affinity beads containing the C-terminal association domain, but does not bind as well as its isolated $\mathrm{N}$-terminal domain. (A) Placental ezrin used for the binding assays (starting material; lane 1). The positions of $81-\mathrm{kDa}$ ezrin (E) and two degradation products (D1 and D2) are indicated. GST alone (lanes 2 and 6) and fusion proteins containing ezrin amino acids 479-585 (lanes 3 and 7), 474-583 (lanes 4 and 8), and 474-585 (lanes 5 and 9) were bound to glutathione-agarose to make affinity beads. The fusion proteins in lanes $4,5,8$, and 9 were expressed in strain DH5 $\alpha$ E. coli cells, which resulted in the appearance of a characteristic proteolytic product (lower band of major doublet) in addition to the intact fusion protein (upper band of major doublet). Beads were incubated with BSA alone $(2 \mathrm{mg} / \mathrm{ml})$ to show bacterial proteins (lanes 2-5) or $1.0 \mu \mathrm{M}$ ezrin mixed with BSA (lanes 6-9). Beads were washed, and the starting and bound material was analyzed by SDS-PAGE and Coomassie blue staining (lanes 1-9) or blot overlay using a biotinylated ezrin probe (lanes $1^{\prime}, 7^{\prime}, 8^{\prime}$, and $\left.9^{\prime}\right)$. The amount of ezrin loaded in lane $1^{\prime}$ was similar to that in lanes $7^{\prime}$ and $9^{\prime}$. (B) Affinity beads containing GST alone (lanes 1 and 4), the ezrin 479-585 (lanes 2 and 5), and 428-585 (lanes 3 and 6) fusion proteins were incubated with $0.3 \mu \mathrm{M}$ placental ezrin mixed with $2 \mathrm{mg} / \mathrm{ml}$ BSA (lanes 1-3) or $0.3 \mu \mathrm{M} 35-\mathrm{kDa}$-terminal proteolytic derivative mixed with BSA (lanes 4-6). Beads were washed, and the bound material was analyzed by SDS-PAGE and Coomassie blue staining. Molecular masses $(\mathrm{kDa})$ are indicated. than when it is present in the $35-\mathrm{kDa}$ fragment indicates that the C-terminal half of ezrin may be inhibitory. Perhaps the C-terminal portion sterically hinders the interaction between the N-ERMAD and the affinity beads. Steric factors may be more significant in affinity bead assays than blot overlays, because the bulky GST moiety fused to the C-ERMAD is native in these instead of denatured.

One explanation for the inhibitory effect of the Cterminal half might be that the C-ERMAD binds the $\mathrm{N}$-ERMAD intramolecularly in the ezrin monomer. If so, one might expect that ezrin would be unable to bind to C-ERMAD-containing affinity beads unless its own C-ERMAD had been degraded or otherwise inactivated. However, blot overlay analysis showed that the bead-bound ezrin possessed fully functional CERMADs. The slot blot assays produced another observation that seems inconsistent with the notion of intramolecular $\mathrm{N}$ - and C-ERMAD association: biotinylated native ezrin displayed N-ERMAD activity under conditions in which its C-ERMAD activity was undetectable. Nevertheless, intramolecular association of ERMADs cannot be absolutely discounted at present. Because the F-actin binding sites of ezrin and moesin are contained within the C-ERMAD, it is conceivable that these proteins use ERMAD-mediated intramolecular self-association as a means to regulate F-actin binding site accessibility. A similar form of regulation has been shown for the cytoskeletal protein vinculin (Johnson and Craig, 1995). Additional investigation will be needed to understand the subtle factors at work in the affinity bead binding experiments at the level of ezrin molecular structure.

\section{Structure of Monomers and Dimers}

With the discovery of complementary association domains in ezrin, models that describe the structures of monomers and dimers can be proposed based on the reasonable assumption that dimer formation involves ERMAD interactions. At present, the only alternative to this hypothesis is that ezrin contains one or more additional association domains whose activity is not displayed by monomeric proteins in solution and cannot be observed in full-length proteins or protein fragments investigated by blot overlay, native slot blot, and affinity bead binding assays.

In these models (Figure 10), an important concept is that the C-ERMAD is masked in the monomer. Consequently, activation would be needed to unmask the C-ERMAD, which is a prerequisite for dimerization. The degree to which conformational factors might also affect N-ERMAD activity is less clear at present. Dimers are depicted without an exposed C-ERMAD because mixtures of monomers and dimers do not spontaneously form trimers in solution. Binding of complementary ERMADs could produce dimers with 

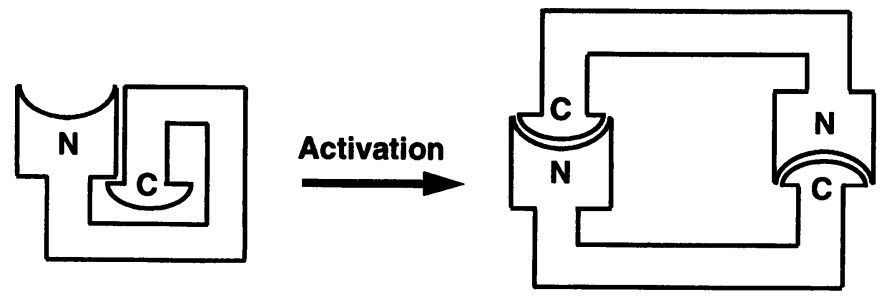

Figure 10. Two possible models for ezrin dimerization. Each illustrates the inaccessible nature of the C-terminal domain in the monomer. The N-ERMAD is depicted as fully accessible, but may in fact be partly occluded (see text for discussion). (A) Dimer with double head-to-tail connection. (B) Dimer with single head-to-tail connection.

\author{
$\mathbf{B}$
}
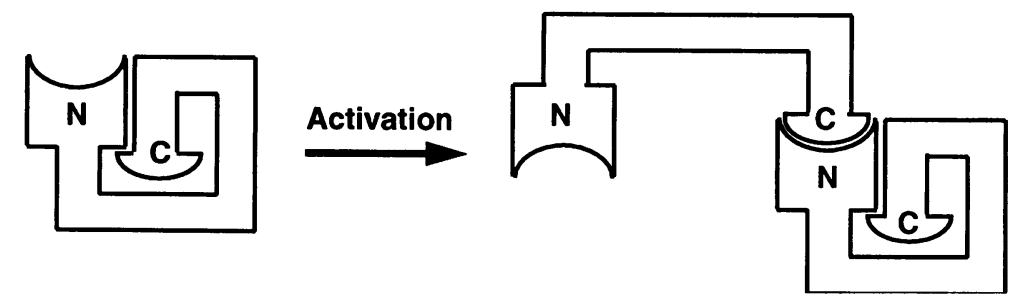

either one or two head-to-tail connections. Dimerization by single head-to-tail joining of distinct domains as depicted in Figure 10B raises the possibility that additional monomers could be added to a growing chain of end-to-end-linked subunits to produce higher order oligomers. Chemical cross-linking of high salt extracts from placental microvilli reveals immunoreactive species of ezrin that appear be dimers, trimers, tetramers, and so on (M. Berryman, personal communication). The possession of $\mathrm{N}$ - and C-ERMADs gives ezrin a molecular design that has the intrinsic potential to form linear macromolecular assemblies in a regulation-dependent manner, a property that might be of much utility for a structural protein thought to have morphogenic activity.

\section{Other Members of the ERM Family also Have ERMADs}

Homology and blot overlay data suggest that ERM family members in addition to ezrin possess functional ERMADs. In blot overlays, ezrin and moesin probes each bind to ezrin, moesin, and radixin targets (Gary and Bretscher, 1993a; Andreoli et al., 1994; Gary, 1995). Thus, all three have SDS-resistant regions that act as C-ERMADs. This region has been mapped to the C-terminal one-half of the molecule for moesin (Gary and Bretscher, 1993b) as well as for ezrin. As a probe, moesin is indistinguishable from full-length or truncated ezrin probes that contain the N-ERMAD; it bound specifically to C-ERMAD targets, and exhibited the lability typical of N-ERMADs. There is currently no experimental evidence for or against the presence of an active N-ERMAD in radixin, although the protein is $86 \%$ identical to ezrin and moesin over this region (Table 1). The similar behaviors of ERM proteins in blot overlays and the existence of ezrin-moesin heterodimers in vivo (Gary and Bretscher, 1993a) sug- gest that ezrin self-association may illustrate principles applicable to a host of ERM family interactions.

The N-ERMAD corresponds to a large structural domain common to members of the band 4.1 superfamily. This superfamily includes erythrocyte band 4.1 , talin, several protein tyrosine phosphatases, the ERM family, and merlin/schwannomin (reviewed in Takeuchi et al., 1994a); all have a $\sim 300$ amino acid $\mathrm{N}$-terminal domain that is at least $23 \%$ identical between members. This domain has been shown to be protease-resistant for band 4.1, ezrin, and moesin, indicating a common structural unit (Leto and Marchesi, 1984; Franck et al., 1993). The folding topology of the domain is probably conserved throughout the superfamily, but there is no evidence that members only distantly related to ezrin possess functional N-ERMADs. The sensitivity of N-ERMAD activity to SDS treatment and freezethawing indicates that native conformation is critical. The boundary of the N-ERMAD matches closely with the end of the conserved portion of the super-

Table 1. Conservation of N- and C-terminal association domains between ezrin and related proteins

\begin{tabular}{lcc}
\hline Protein & $\begin{array}{c}\text { N-terminal } \\
(\%)^{\mathrm{a}}\end{array}$ & $\begin{array}{c}\mathrm{C} \text {-terminal } \\
(\%)^{\mathrm{b}}\end{array}$ \\
\hline Human ezrin & 100 & 100 \\
Human radixin & 86 & 60 \\
Human moesin & 85 & 58 \\
Human merlin I/II & 61 & $24 / 22$ \\
Echinococcus multilocularis EM10 & 57 & 39 \\
\hline
\end{tabular}

a Percent identity to ezrin amino acids 1-296.

b Percent identity to ezrin amino acids 479-585.

c Alternately spliced forms (Bianchi et al., 1994). 
family, so ezrin residues 1-296 may constitute the shortest sequence capable of proper folding.

Among band 4.1 superfamily members, only the tumor suppressor merlin (Rouleau et al., 1993; Trofatter et al., 1993) is very closely related to the ERM proteins (47\% identity overall). Sequence conservation between ezrin and merlin is high in the region of the N-ERMAD but low for the C-ERMAD. The substantial divergence in merlin of the C-ERMAD relative to the N-ERMAD is particularly apparent in comparison to the phylogenetically distant ERM homologue EM10 (Frosch et al., 1991) from the tapeworm Echinococcus multilocularis (Table 1). This pattern of conservation raises the possibility that the N-ERMAD of merlin is active as an ERM association domain but its C-ERMAD is not. If so, merlin would be unable to selfassociate, but might nonetheless heterodimerize with activated ERM proteins. The genetic behavior of tumor suppressors indicates an inhibitory function; mutation of both alleles leads to loss of proliferative control. In contrast, up-regulation of ezrin expression has been correlated with oncogenic transformation (Fazioli et al., 1993; Jooss and Muller, 1995). Perhaps merlin sequesters activated ezrin monomers, whose C-termini have been exposed by mitogenic signals, to give heterodimers that do not promote proliferation. Merlin overexpression can counteract the transforming activity of Ras (Tikoo et al., 1994), an oncoprotein that targets Raf to the plasma membrane (reviewed in McCormick, 1994). Importantly, the N-terminal onehalf of merlin, containing the putative N-ERMAD, is nearly as effective as full length. Raf activation appears also to require phosphorylation by Src (Williams et al., 1992; Fabian et al., 1994; Leevers et al., 1994; Marshall, 1995), and ezrin is a Src kinase substrate (Kamps et al., 1986) that can bind to the SH2 domain of Src in an EGF-dependent manner (our unpublished observation). Perhaps merlin dampens a process that depends upon ERM complexes to correctly juxtapose interacting signaling molecules at submembraneous foci.

\section{Perspectives}

Proteins of the ERM family possess unique domains, here referred to as N-ERMADs and C-ERMADs, that could theoretically mediate a combinatorial assortment of homo- and heterotypic associations. Restricted coexpression of ezrin, radixin, moesin, and merlin is one way in which the number of possibilities may be controlled in a tissue-specific manner. In addition, oligomerization appears to be tightly regulated through masking of the C-ERMAD. The ERM proteins have evolved an unusual head-to-tail mechanism for association that has the potential to be rapidly activated by induced conformational change. Such a design virtually assures that oligomerization is physiologically important; it implies that ERM complexes have capabilities that monomers do not. The challenge ahead is to discover the functional consequences of oligomerization and the details of its regulation.

\section{ACKNOWLEDGMENTS}

We thank Dr. Mark Berryman for critically reading the manuscript and for sharing unpublished data. This work was supported by National Institutes of Health grant GM-36652 (to A.B.).

\section{REFERENCES}

Algrain, M., Turunen, O., Vaheri, A., Louvard, D., and Arpin, M. (1993). Ezrin contains cytoskeleton and membrane binding domains accounting for its proposed role as a membrane-cytoskeletal linker. J. Cell Biol. 120, 129-139.

Amieva, M.R., Wilgenbus, K.K., and Furthmayr, H. (1994). Radixin is a component of hepatocyte microvilli in situ. Exp. Cell Res. 210, 140-144.

Andreoli, C., Martin, M., Le Borgne, R., Reggio, H., and Mangeat, P. (1994). Ezrin has properties to self-associate at the plasma membrane. J. Cell Sci. 107, 2509-2521.

Ausubel, F.M., Brent, R., Kingston, R.E., Moore, D.D., Seidman, J.G., Smith, J.A., and Struhl, K. (1994). Current Protocols in Molecular Biology, New York: John Wiley and Sons.

Berryman, M., Franck, Z., and Bretscher, A. (1993). Ezrin is concentrated in the apical microvilli of a wide variety of epithelial cells whereas moesin is found primarily in endothelial cells. J. Cell Sci. 105, 1025-1043.

Bianchi, A.B., Hara, T., Ramesh, V., Gao, J., Klein-Szanto, A.J.P., Morin, F., Menon, A.G., Trofatter, J.A., Gusella, J.F., Seizinger, B.R., and Kley, N. (1994). Mutations in transcript isoforms of the neurofibromatosis 2 gene in multiple human tumour types. Nature Genetics 6, 185-192.

Bretscher, A. (1983). Purification of an 80,000-dalton protein that is a component of the isolated microvillus cytoskeleton, and its localization in nonmuscle cells. J. Cell Biol. 97, 425-432.

Bretscher, A. (1989). Rapid phosphorylation and reorganization of ezrin and spectrin accompany morphological changes induced in A-431 cells by epidermal growth factor. J. Cell Biol. 108, 921-930.

Bretscher, A. (1991). Microfilament structure and function in the cortical cytoskeleton. Annu. Rev. Cell Biol. 7, 337-374.

Egerton, M., Burgess, W.H., Chen, D., Druker, B.J., Bretscher, A., and Samelson, L.E. (1992). Identification of ezrin as an $81-\mathrm{kDa}$ tyrosine-phosphorylated protein in T cells. J. Immunol. 149, 18471852.

Fabian, J.R., Vojtek, A.B., Cooper, J.A., and Morrison, D.K. (1994). A single amino acid change in Raf-1 inhibits Ras binding and alters Raf-1 function. Proc. Natl. Acad. Sci. USA 91, 5982-5986.

Fazioli, F., Wong, W.T., Ullrich, S.J., Sakaguchi, K., Appella, E., and Di Fiore, P.P. (1993). The ezrin-like family of tyrosine kinase substrates: receptor-specific pattern of tyrosine phosphorylation and relationship to malignant transformation. Oncogene 8, 1335-1345.

Franck, Z., Gary, R., and Bretscher, A. (1993). Moesin, like ezrin, colocalizes with actin in the cortical cytoskeleton in cultured cells, but its expression is more variable. J. Cell Sci. 105, 219-231.

Frosch, P.M., Frosch, M., Pfister, T., Schaad, V., and Bitter-Suermann, D. (1991). Cloning and characterization of an immunodominant major surface antigen of Echinococcus multilocularis. Mol. Biochem. Parasitol. 48, 121-130. 
Funayama, N., Nagafuchi, A., Sato, N., Tsukita, Sa., and Tsukita, Sh. (1991). Radixin is a novel member of the band 4.1 family. J. Cell Biol. $115,1039-1048$.

Gary, R. (1995). Associations between members of the ezrin family of membrane-cytoskeletal linking proteins. Doctoral dissertation. Ithaca, NY: Cornell University.

Gary, R., and Bretscher, A. (1993a). Heterotypic and homotypic associations between ezrin and moesin, two putative membranec ftoskeletal linking proteins. Proc. Natl. Acad. Sci. USA 90, 1084610850.

Gary, R., and Bretscher, A. (1993b). Mapping the hetero- and homotypic association domains of ezrin and moesin. Mol. Biol. Cell 4, 170 .

Goslin, K., Birgbauer, E., Banker, G., and Solomon, F. (1989). The role of cytoskeleton in organizing growth cones: a microfilamentassociated growth cone component depends upon microtubules for its localization. J. Cell Biol. 109, 1621-1631.

Gould, K.L., Bretscher, A., Esch, F.S., and Hunter, T. (1989). cDNA cloning and sequencing of the protein-tyrosine kinase substrate, ezrin, reveals homology to band 4.1. EMBO J. 8, 4133-4142.

Hanzel, D., Reggio, H., Bretscher, A., Forte, J.G., and Mangeat, P. (1991). The secretion-stimulated $80 \mathrm{~K}$ phosphoprotein of parietal cells is ezrin, and has properties of a membrane cytoskeletal linker in the induced apical microvilli. EMBO J. 10, 2363-2373.

Johnson, R.P., and Craig, S.W. (1995). F-actin binding site masked by the intramolecular association of vinculin head and tail domains. Nature 373, 261-264.

Jooss, K.U., and Muller, R. (1995). Deregulation of genes encoding microfilament-associated proteins during Fos-induced morphological transformation. Oncogene 10, 603-608.

Kamps, M.P., Buss, J.E., and Sefton, B.M. (1986). Rous sarcoma virus-transforming protein lacking myristic acid phosphorylates known polypeptide substrates without inducing transformation. Cell 45, 105-112.

Lankes, W.T., and Furthmayr, H. (1991). Moesin: a member of the protein 4.1-talin-ezrin family of proteins. Proc. Natl. Acad. Sci. USA 88, 8297-8301.

Leevers, S.J., Paterson, H.F., and Marshall, C.J. (1994). Requirement for Ras in Raf activation is overcome by targeting Raf to the plasma membrane. Nature 369, 411-414.

Leto, T.L., and Marchesi, V.T. (1984). A structural model of human erythrocyte protein 4.1. J. Biol. Chem. 259, 4603-4608.

Marshall, C.J. (1995). Specificity of receptor tyrosine kinase signaling: transient versus sustained extracellular signal-regulated kinase activation. Cell 80, 179-185.

Martin, M., Andreoli, C., Sahuquet, A., Montcourrier, P., Algrain, M., and Mangeat, P. (1995). Ezrin $\mathrm{NH}_{2}$-terminal domain inhibits the cell extension activity of the $\mathrm{COOH}$-terminal domain. J. Cell Biol. 128, 1081-1093.

McCormick, F. (1994). Raf: the Holy Grail of Ras biology? Trends Cell Biol. 4, 347-350.

Okayama, H., and Berg, P. (1982). High-efficiency cloning of fulllength cDNA. Mol. Cell. Biol. 2, 161-170.

Pakkanen, R., Hedman, K., Turunen, O., Wahlstrom, T., and Vaheri, A. (1987). Microvillus-specific $M_{r} 75,000$ plasma membrane protein of human choriocarcinoma cells. J. Histochem. Cytochem. 35, 809816.
Pakkanen, R., and Vaheri, A. (1989). Cytovillin and other microvillar proteins of human choriocarcinoma cells. J. Cell. Biochem. 41, 1-12.

Pestonjamasp, K., Amieva, M.R., Strassel, C.P., Nauseef, W.M., Furthmayr, H., and Luna, E.J. (1995). Moesin, ezrin, and p205 are actin-binding proteins associated with neutrophil plasma membranes. Mol. Biol. Cell 6, 247-259.

Rouleau, G.A., Merel, P., Lutchman, M., Sanson, M., Zucman, J., Marineau, C., Hoang-Xuan, K., Demczuk, S., Desmaze, C., Plougastel, B., Pulst, S.M., Lenoir, G., Bijlsma, E., Fashold, R., Dumanski, J., de Jong, P., Parry, D., Eldrige, R., Aurias, A., Delattre, O., and Thomas, G. (1993). Alteration in a new gene encoding a putative membrane-organizing protein causes neuro-fibromatosis type 2 . Nature 363, 515-521.

Sato, N., Funayama, N., Nagafuchi, A., Yonemura, S., Tsukita, Sa., and Tsukita, Sh. (1992). A gene family consisting of ezrin, radixin and moesin: its specific localization at actin filament/plasma membrane association sites. J. Cell Sci. 103, 131-143.

Shuster, C.B., and Herman, I.M. (1995). Indirect association of ezrin with F-actin: isoform specificity and calcium sensitivity. J. Cell Biol. $128,837-848$

Takeuchi, K., Kawashima, A., Nagafuchi, A., and Tsukita, S. (1994a). Structural diversity of band 4.1 superfamily members. J. Cell Sci. 107, 1921-1928.

Takeuchi, K., Sato, N., Kasahara, H., Funayama, N., Nagafuchi, A., Yonemura, S., Tsukita, Sa., and Tsukita, Sh. (1994b). Perturbation of cell adhesion and microvilli formation by antisense oligonucleotides to ERM family members. J. Cell Biol. 125, 1371-1384.

Thuillier, L., Hivroz, C., Fagard, R., Andreoli, C., and Mangeat, P. (1994). Ligation of CD4 surface antigen induces rapid tyrosine phosphorylation of the cytoskeletal protein ezrin. Cell. Immunol. 156, 322-331.

Tikoo, A., Varga, M., Ramesh, V., Gusella, J., and Maruta, H. (1994). An anti-Ras function of neurofibromatosis type 2 gene product (NF2/merlin). J. Biol. Chem. 269, 23387-23390.

Trofatter, J.A., MacCollin, M.M., Rutter, J.L., Murrell, J.R., Duyao, M.P., Parry, D.M., Eldridge, R., Kley, N., Menon, A.G., Pulaski, K., Haase, V.H., Ambrose, C.M., Munroe, D., Bove, C., Haines, J.L., Martuza, R.L., MacDonald, M.E., Seizinger, B.R., Short, M.P., Buckler, A.J., and Gusella, J.F. (1993). A novel moesin-, ezrin-, radixinlike gene is a candidate for the neurofibromatosis 2 tumor suppressor. Cell 72, 791-800.

Tsukita, Sa., Oishi, K., Sato, N., Sagara, J., Kawai, A., and Tsukita, Sh. (1994). ERM family members as molecular linkers between the cell surface glycoprotein CD44 and actin-based cytoskeletons. J. Cell Biol. 126, 391-401.

Turunen, O., Wahlstrom, T., and Vaheri, A. (1994). Ezrin has a $\mathrm{COOH}$-terminal actin-binding site that is conserved in the ezrin protein family. J. Cell Biol. 126, 1445-1453.

Turunen, O., Winqvist, R., Pakkanen, R., Grzeschik, K.-H., Wahlstrom, T., and Vaheri, A. (1989). Cytovillin, a microvillar $M_{\mathrm{r}} 75,000$ protein: cDNA sequence, prokaryotic expression, and chromosomal localization. J. Biol. Chem. 264, 16727-16732.

Ullrich, S.J., Robinson, E.A., and Appella, E. (1986). Characterization of a chemically homogeneous tumor antigen from a methylcholanthrene-induced sarcoma, Meth A. Mol. Immunol. 23, 545-555.

Williams, N.G., Roberts, T.M., and Li, P. (1992). Both p21 ${ }^{\text {ras }}$ and pp60 ${ }^{\mathrm{v}-\mathrm{src}}$ are required, but neither alone is sufficient, to activate the Raf-1 kinase. Proc. Natl. Acad. Sci. USA 89, 2922-2926. 